\title{
Epidemiology of paediatric trauma in Hong Kong: A multicentre cohort study
}

\author{
C.B. Chow ${ }^{\mathrm{a}}$, M. Leung ${ }^{\mathrm{b}, *}$, Gilberto K.K. Leung ${ }^{\mathrm{c}}$, W.Y. Shen ${ }^{\mathrm{d}}$, C.W. Kam ${ }^{\mathrm{e}}$, H.M. Cheung, \\ K.L. Auyeung ${ }^{g}$, Patrick Ip ${ }^{\text {h }}$ \\ a Department of Paediatrics and Adolescent Medicine, LKS Faculty of Medicine, The University of Hong Kong, Hong Kong, China \\ b Central Nursing Division, Princess Margaret Hospital, Hong Kong, China \\ ${ }^{c}$ Department of Surgery, The University of Hong Kong/Queen Marry Hospital, Hong Kong, China \\ ${ }^{\mathrm{d}}$ Hospital authority, Queen Elizabeth Hospital, Hong Kong, China \\ e Tuen Mun Hospital, Hong Kong, China \\ ${ }^{\mathrm{f}}$ Department of Paediatrics, Chinese University of Hong Kong, Hong Kong, China \\ ${ }^{g}$ Queen Elizabeth Hospital, United Kingdom \\ h Department of Paediatrics and Adolescent Medicine, LKS Faculty of Medicine, The University of Hong Kong, Hong Kong
}

\section{A R T I C L E I N F O}

\section{Keywords:}

Paediatric trauma

Trauma

Epidemiology

Injury severity

\begin{abstract}
A B S T R A C T
Introduction: Trauma is the commonest cause of death and major morbidities in children and adolescents worldwide. There has been a lack of data on the epidemiology of trauma among children in Chinese cities include Hong Kong. Therefore the current study was conducted to examine the spectrum of paediatric trauma in Hong Kong and to address knowledge gaps in its epidemiology and prevention.

Objective: This study aimed to describe the epidemiological features of paediatric trauma and explore the characteristics in the low income group which would help to guide the design of effective interventions and future research on prevention of paediatric trauma.

Method: A descriptive study on the epidemiology of trauma in children $\leq 18$-year-old using a standardised injury registry embedded within a population-based hospital database. Information on demographics, injury type, mechanism, injury severity score (ISS) and injury prevention prioritization score (IPPZ) were collected to identify the epidemiological features and prevention initiatives.

Result: The overall female to male ratio was 1: 1.97, which increased with age from 1:1.45 (infant; below 2 years old) to 1:2.67 (adolescent; 12-18 years old). The overall mean ISS was 7.98 (SD 9.18), ISS increased with age significantly ( $r h o=0.143, \mathrm{P}<0.001$ ). The most common context of trauma included travelling (IPPZ: 59.94, mean ISS $10.2 \pm 10.23, \mathrm{n}=402$ ), leisure activities (IPPZ: 52.04 , mean ISS $5.6 \pm 6.77, \mathrm{n}=312$ ), street/ highway (IPPZ: 70.22, mean ISS $10.48 \pm 10.53, \mathrm{n}=475$ ) and home (including garden and out buildings) (IPPZ: 69.56 , mean ISS $6.64 \pm 7.94, \mathrm{n}=539$ ). Severity of paediatric injuries among low-income group did not differ from the general population.

Conclusion: The study provided updated epidemiological characteristics of paediatric trauma, which could be used to guide focus prevention of paediatric trauma. The findings also highlighted further study initiatives including injury surveillance, geographical analysis and environment modification.
\end{abstract}

\section{Introduction}

Child injury is a major public health concern globally. It accounted for the death of 950,000 children under the age of 18 years annually, among which $90 \%$ were unintentional injuries and $10 \%$ were related to violence and maltreatment. ${ }^{1}$ In the United States, the overall unintentional injury mortality was 15.0 per 100,000 children. $^{2}$ There were evidenced variations of rates; age, gender and mode of injuries exist along the range of age from 0 to 18 years. According to the CDC Childhood Injury Report 2000-2006, ${ }^{3}$ suffocation and falls were the major causes of injury among children aged less than 4; while drowning, car crash - occupant and struck against an object were the major causes of injury among those aged between 4 to 19 years. Unintentional injury was found to be a leading cause of child death and disability in Hong Kong. Among children (age 1-4) and youth (age 5-14), injury and poisoning led to 3.1 deaths per 100,000 and 3.7

\footnotetext{
* Corresponding author at: Nurse Consultant (Trauma), A\&E Office, Princess Margaret Hospital, Hong Kong.

E-mail address: leungm1@ha.org.hk (M. Leung).
} 
deaths per 100,000 respectively. From the Child and Health Survey conducted in 2005 to 2006 in Hong Kong, the prevalence of injury that needed medical advice or treatment in children aged 14 and below was $4.4 \% .{ }^{4}$ Local studies had shown that cause of injury varies in two age dimensions, infants (age 0 to 1 ) were associated with falls, poisoning, scalds, and machinery related injury. Adolescent (age 12 to 15) injuries were due to motor related injury, animal related injury, and cuts/ piercings ${ }^{5}$ and fall was the major characteristic along the age from 0 to 15 years ${ }^{6}$ In reality, injury was a common cause of death, hospitalisation and disability among paediatric population globally, which imposes significant burden to the individual and society subsequently.

Most of the injury incidents and trauma deaths were preventable and knowledge of the epidemiology was essential for developing preventive strategies. The epidemiology of injury includes studying of the characteristics of time, place, host and vector. ${ }^{7}$ There were pressing needs to gain deeper understanding into epidemiological factors, which not only enhanced knowledge on unique aetiology of paediatric trauma but also helped to improve the health practice and outcome. It would be essential in reducing the occurrence of such events, with evidence based insights on severity and causes of injury and the resulting mortality. ${ }^{8,9}$ On the other hand, economic deprivation should also be considered as western study has identified a higher injury rate in preadolescent children and in the school playground for the low-income group ${ }^{10}$ and more children from deprived areas attended with head injured. ${ }^{11}$

Given trauma as the greatest reason of morbidity and mortality in paediatric populations worldwide ${ }^{12}$ and a recent literature search has identified only six relevant papers identified for Hong Kong with the latest studies being done in $2003,{ }^{6}$ attention should be paid to paediatric trauma population. There was certainly a need of conducting a study on the spectrum of paediatric trauma in Hong Kong, and to address knowledge gaps in epidemiology and prevention.

\section{Objective}

This research aimed to describe the epidemiological features of paediatric trauma in Hong Kong and explore the characteristics in the low income group that helping to suggest the prevention focus and further research initiatives.

\section{Methods}

\subsection{Data source}

Data was retrieved from the standardised trauma registry at the five designated trauma centres in Hong Kong, named Prince of Wales Hospital (PWH), Princess Margaret Hospital (PMH), Queen Elizabeth Hospital (QEH), Queen Mary Hospital (QMH) and Tuen Mun Hospital (TMH). The registry data represent the information from majority of the trauma population in Hong Kong since the arrangement of prehospital trauma diversion and secondary trauma diversion existed in 2006. The arrangement concentrated those trauma patients to be handled in the five designated trauma centres with local trauma system in place. The registry data set was separated as inpatient cohort and emergency attendance analysis. Each episode was distinguished by distinct hospital registration number. Chart review was conducted to identify majority of the data in the core data set and to extract supplementary data for traffic, self-harm and assault related injuries. Using the data from the trauma registry and the hospital authority's database, previous publications have been made to share the implications, improvement and outcomes on clinical perspective. ${ }^{13-18}$ The trauma registry inclusion criteria had been standardized among the five centres as:

1. Trauma team activation has been made

2. Triaged as critical or serious at emergency department

3. Primary or secondary diverted to the trauma centres
4. Admission to Intensive Care Unit or High Dependency Unit during hospital stay

\subsection{Data collection}

A retrospective review of patient demographics, injury type, mechanism and outcomes has been conducted using data from the five centres' trauma registries from January 2007 to December 2013. Age criteria was be made reference to the World Health Organization (WHO) position paper for 0 to 18 years of age, with five age group classifications: neonate, infant, young child, child, adolescent. ${ }^{19}$ The data set included the patient demographics, hospital processing information, classified activities and places of injury, Abbreviated Injury Scale (AIS), Injury Severity Scores (ISS) and related E codes.

\subsection{Analysis}

The study framework referred to the epidemiological models of injury and the classified factors as host, agent, vector and environment, which exhibits the important features in the epidemiological perspective and facilitate further understanding of the unique aetiology of paediatric trauma. SPSS 22 was used to perform Descriptive statistics, inferential statistics and correlation analysis in order to identify the epidemiological focus and prevention initiatives along the injury spectrum.

Prevention Priority Score (IPPZ) was computed from firstly the two $\mathrm{z}$ scores from the estimated mean and standard deviation of the frequencies and mean ISS of each epidemiological category. Then, compute another $\mathrm{z}$ scores from dividing each sum of the two $\mathrm{z}$ scores by the $\mathrm{SD}$ of the sum of the two $\mathrm{z}$ scores. These new $\mathrm{z}$-score have mean $=0$ and $\mathrm{SD}=1$. The IPPZ was computed from a $\mathrm{T}$ score $(\mathrm{T}=50+10[\mathrm{z}])$. The resulting IPPZ have mean of 50 and an SD of 10 by definition. ${ }^{8}$

\subsection{Ethics}

The identity of cases had been concealed. Further, all associates, colleagues, and staffs assisted in the process of conducting the study were informed about their obligations in compliance with ethical guidelines. Encryption of data had been made for security maintenance. In addition, no personal identity was kept in the dataset and a pseudo code had been assigned and used in data analysis. The investigators were required declaring any potential conflicts of interest that might arise. Ethical approval has been sought from the ethic committee at the 5 clusters where the trauma centres were located.

\section{Result}

\subsection{Age and gender}

There were 1,691 records retrieved for the study. The overall female to male ratio was 1: 1.97, which increased with age from 1:1.45 (infant; below 2 years old) to 1:2.67 (adolescent; $12-18$ years old). Fig. 1 shows similar distribution of age between the genders. The pattern was constricting from the peak of 1 year (male: $11.23 \%$, female: $13.88 \%$ ) to 8 years (male $2.32 \%$, female: $3.34 \%$ ) and then expanding towards 18 years of age (Fig. 1).

\subsection{Injury severity score (ISS)}

There were 1,710 AIS scores assigned from chart review with majority were assigned to head/neck and external (head/neck, $\mathrm{n}=735$; face, $\mathrm{n}=155$; thorax, $\mathrm{n}=101$; abdomen, $\mathrm{n}=133$; extremities, $\mathrm{n}=309$; external, $\mathrm{n}=1,012$ ). For severe and critical AIS scale of 4 and 5,363 scale were assigned with majority assigned to head/neck (head/ neck, $\mathrm{n}=276$; thorax, $\mathrm{n}=39$; abdomen, $\mathrm{n}=12$; extremities, $\mathrm{n}=17$; external, $n=19$ ). The overall mean injury severity scale (ISS) was 7.98 


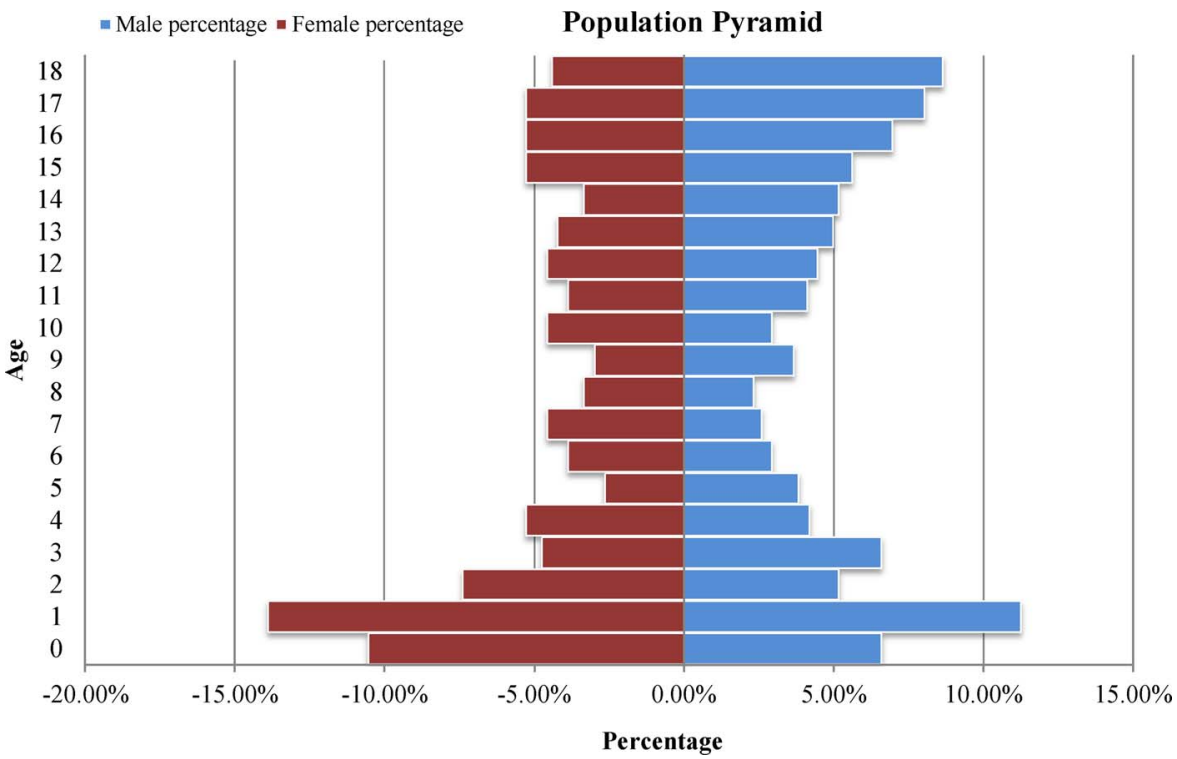

Fig. 1. Population pyramid of the paediatric trauma 2007-2013, Hong Kong.

Distribution of injury severity scale by gender

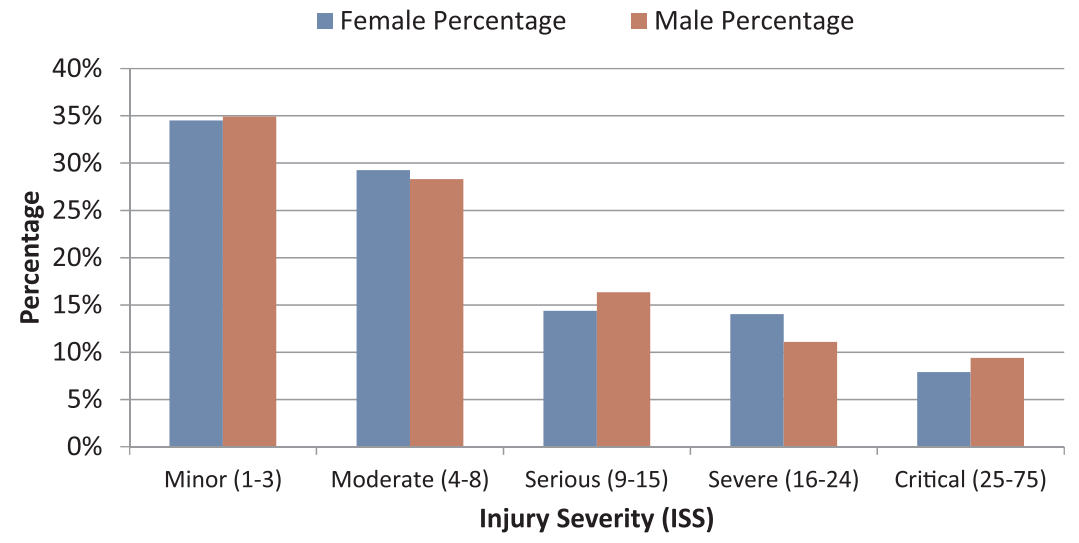

Fig. 2. Distribution of injury severity scale by gender.

(SD 9.18) which was calculated by the summation of the square of top three assigned AIS scores. Similar pattern of distribution was found between injury severity scale (ISS) and genders (Fig. 2). The proportion stratified by injury severity decreased from minor injury (ISS1-3) to critical (ISS 25-75). The range of injury scale among age groups and the ISS was found to be increased with age significantly (rho $=0.143$, $\mathrm{P}<0.001$ ) (Fig. 3).

\subsection{Epidemiological features}

Unintentional injuries played the major portion across the age group with range from $79.14 \%$ to $97.96 \%$. The overall top activities were travelling ( $n=402,23.77 \%$ ), which represented the similar findings in the age group of $7-11$ years $(n=104,36.49 \%)$ and $12-18$ years ( $n=224,33.14 \%$ ). However, different observation was made to the younger age group with major proportion focused on leisure activities (below 2 years: $\mathrm{n}=94,27.81 \%$ and $2-6$ years: $\mathrm{n}=128,32.65 \%$ ). With increasing age, the portion of sport injury also increased from year of 7 while the educational related activities still maintained a very low portion along the all age groups. On the other hand, home (including garden and out buildings) $(\mathrm{n}=539,31.87 \%)$ and street/highway ( $n=475,28.09 \%$ ) were found to be the common place of injury occurrence, which represented the similar findings in the younger age groups of below 2 years $(n=244,72.19 \%)$ and $2-6$ years $(n=181$, $46.17 \%$ ). In opposition, street/highway was the top place of injury occurrence since the year of 7 (7-11 years: $n=114,40 \%, 12-18$ years: $\mathrm{n}=277,40.98 \%$ ). Home (including garden and out buildings) and sports and athletics area were also the concern area the elder group above the 7 years old. Further analysis by mechanism with E codes, 306 (21.29\%)(incidences was happened from traffic accident, which included 155 incidences within the age between 12-18 years and the number decreased with age. Also, 70 incidences were related to pedal cycle accident (E826.9) with 59 head injured. There were 249 incidences related to fall (E880.0, E880.9, E881, E882, E883.9, E884.9 and E886.9) with various sources including ladder, playground equipment and bed. Scald was also another concern that 211 incidences related to hot liquid and steam (E924.0) and more than 50\% $(n=128)$ occurred below the age of 2 years (Table 1 ).

\subsection{Temporal features}

The overall annual number of incidence ranged from 317 (18.75\%) to $313(22.24 \%)$. There was no association between the year and the number of incidence was found, $X^{2}(6, \mathrm{n}=1,691)=3.646, \mathrm{p}=0.724$. The average monthly number of incidence ranged from $110(6.51 \%)$ to $187(11.06 \%)$. The monthly number for male was always greater than 
Box plot of the injury severity scale by age group $(\mathrm{P}<0.001)$

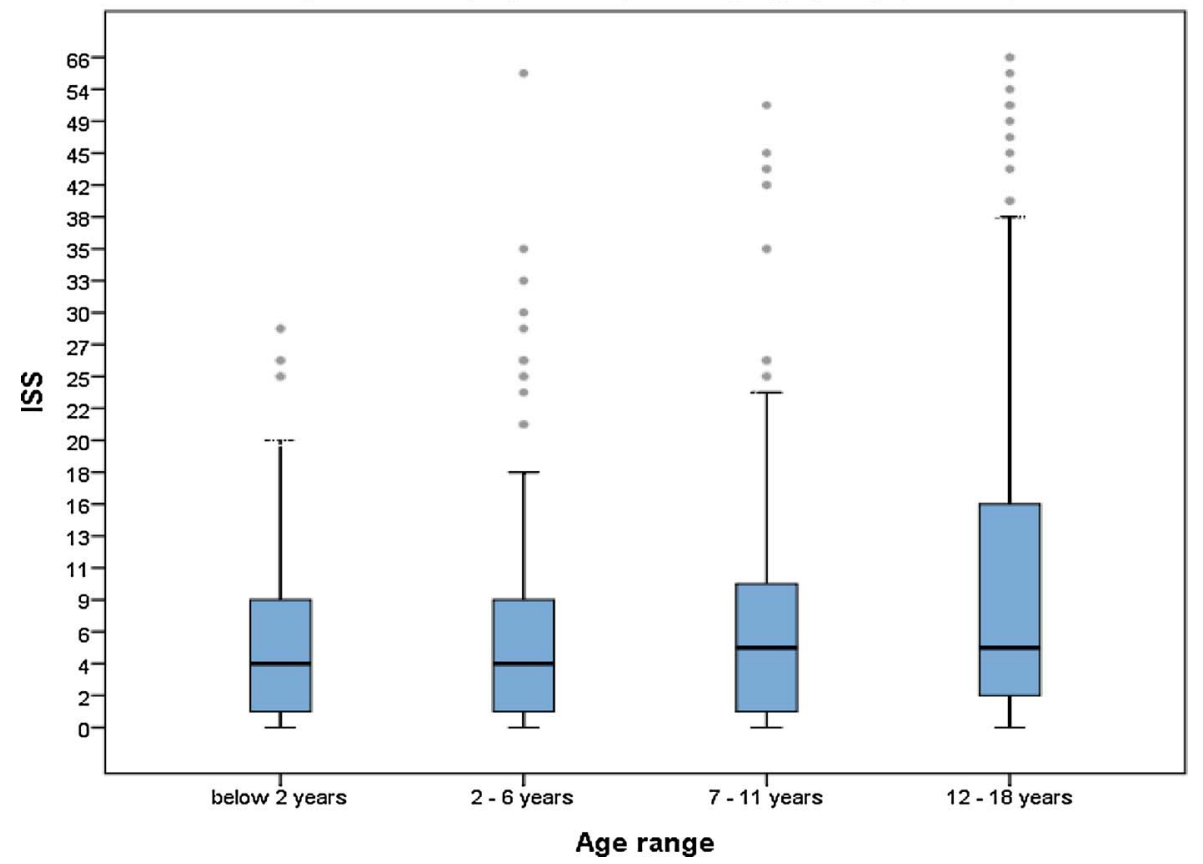

Fig. 3. Box plot of the injury severity scale by age group $(\mathrm{P}<0.001)$.

Table 1

Epidemiological features of paediatric trauma admissions to the five trauma centers in Hong Kong.

\begin{tabular}{|c|c|c|c|c|c|c|c|c|c|c|}
\hline & \multicolumn{2}{|c|}{ Below 2 years (Column\%) } & \multicolumn{2}{|c|}{ 2-6 years (Column\%) } & \multicolumn{2}{|c|}{ 7-11 years (Column\%) } & \multicolumn{2}{|c|}{ 12-18 years (Column\%) } & \multicolumn{2}{|c|}{ Total (Column\%) } \\
\hline \multicolumn{11}{|l|}{ Gender } \\
\hline Female & 138 & $(40.83)$ & 137 & (34.95) & 110 & $(38.60)$ & 184 & $(27.22)$ & 569 & (33.65) \\
\hline Male & 200 & (59.17) & 255 & $(65.05)$ & 175 & $(61.40)$ & 492 & (72.78) & 1122 & (66.35) \\
\hline Total & 338 & & 392 & & 285 & & 676 & & 1691 & \\
\hline \multicolumn{11}{|l|}{ Intent } \\
\hline Unintentional & 324 & $(95.86)$ & 384 & (97.96) & 271 & (95.09) & 535 & (79.14) & 1514 & (89.53) \\
\hline Self-harm & 0 & $(0.00)$ & 0 & $(0.00)$ & 3 & $(1.05)$ & 46 & $(6.80)$ & 49 & $(2.90)$ \\
\hline Assault & 1 & $(0.30)$ & 4 & (1.02) & 4 & $(1.40)$ & 80 & (11.83) & 89 & $(5.26)$ \\
\hline Other & 2 & $(0.59)$ & 1 & $(0.26)$ & 1 & $(0.35)$ & 0 & $(0.00)$ & 4 & $(0.24)$ \\
\hline Unknown & 11 & $(3.25)$ & 3 & $(0.77)$ & 6 & $(2.11)$ & 15 & $(2.22)$ & 35 & $(2.07)$ \\
\hline \multicolumn{11}{|l|}{ Activities } \\
\hline Work related & 0 & $(0.00)$ & 0 & $(0.00)$ & 0 & $(0.00)$ & 21 & (3.11) & 21 & (1.24) \\
\hline Educational activities & 0 & $(0.00)$ & 2 & $(0.51)$ & 3 & $(1.05)$ & 11 & (1.63) & 16 & $(0.95)$ \\
\hline Sports & 1 & $(0.30)$ & 12 & $(3.06)$ & 32 & $(11.23)$ & 86 & (12.72) & 131 & $(7.75)$ \\
\hline Leisure activities & 94 & $(27.81)$ & 128 & $(32.65)$ & 40 & $(14.04)$ & 50 & $(7.40)$ & 312 & (18.45) \\
\hline Travelling & 6 & $(1.78)$ & 68 & (17.35) & 104 & $(36.49)$ & 224 & $(33.14)$ & 402 & (23.77) \\
\hline Other & 109 & $(32.25)$ & 74 & $(18.88)$ & 40 & $(14.04)$ & 82 & (12.13) & 305 & (18.04) \\
\hline Unknown & 128 & $(37.87)$ & 108 & $(27.55)$ & 66 & $(23.16)$ & 202 & $(29.88)$ & 504 & $(29.80)$ \\
\hline \multicolumn{11}{|l|}{ Place of Injury } \\
\hline Home, including garden and out buildings & 244 & (72.19) & 181 & $(46.17)$ & 54 & $(18.95)$ & 60 & $(8.88)$ & 539 & (31.87) \\
\hline $\begin{array}{c}\text { School, including kindergarten and } \\
\text { schoolyard }\end{array}$ & 0 & $(0.00)$ & 7 & $(1.79)$ & 14 & $(4.91)$ & 25 & $(3.70)$ & 46 & $(2.72)$ \\
\hline Street/highway & 7 & $(2.07)$ & 77 & $(19.64)$ & 114 & $(40.00)$ & 277 & $(40.98)$ & 475 & $(28.09)$ \\
\hline Residential institution & 3 & $(0.89)$ & 8 & $(2.04)$ & 3 & $(1.05)$ & 14 & $(2.07)$ & 28 & $(1.66)$ \\
\hline Sports and athletics area & 1 & $(0.30)$ & 16 & $(4.08)$ & 32 & $(11.23)$ & 73 & $(10.80)$ & 122 & $(7.21)$ \\
\hline Other transport area & 1 & $(0.30)$ & 1 & $(0.26)$ & 2 & $(0.70)$ & 13 & $(1.92)$ & 17 & (1.01) \\
\hline Industrial/construction & 0 & $(0.00)$ & 0 & $(0.00)$ & 0 & $(0.00)$ & 21 & (3.11) & 21 & (1.24) \\
\hline Farm, excluding home & 0 & $(0.00)$ & 1 & $(0.26)$ & 1 & $(0.35)$ & 0 & $(0.00)$ & 2 & $(0.12)$ \\
\hline Commercial & 14 & $(4.14)$ & 16 & (4.08) & 11 & $(3.86)$ & 11 & (1.63) & 52 & $(3.08)$ \\
\hline Countryside, water, sea & 0 & $(0.00)$ & 2 & $(0.51)$ & 5 & (1.75) & 6 & $(0.89)$ & 13 & $(0.77)$ \\
\hline Other & 6 & $(1.78)$ & 21 & $(5.36)$ & 12 & $(4.21)$ & 42 & $(6.21)$ & 81 & (4.79) \\
\hline Unknown & 62 & (18.34) & 62 & $(15.82)$ & 37 & $(12.98)$ & 134 & (19.82) & 295 & (17.45) \\
\hline \multicolumn{11}{|l|}{ Trauma Centers Admission } \\
\hline $\mathrm{PMH}$ & 51 & (15.09) & 78 & (19.90) & 64 & $(22.46)$ & 113 & (16.72) & 306 & (18.10) \\
\hline PWH & 73 & $(21.60)$ & 70 & $(17.86)$ & 51 & (17.89) & 160 & $(23.67)$ & 354 & (20.93) \\
\hline QEH & 93 & $(27.51)$ & 82 & $(20.92)$ & 67 & $(23.51)$ & 155 & (22.93) & 397 & $(23.48)$ \\
\hline $\mathrm{QMH}$ & 64 & (18.93) & 102 & $(26.02)$ & 57 & $(20.00)$ & 98 & $(14.50)$ & 321 & (18.98) \\
\hline TMH & 57 & $(16.86)$ & 60 & $(15.31)$ & 46 & $(16.14)$ & 150 & (22.19) & 313 & (18.51) \\
\hline
\end{tabular}


Table 2

Temporal features of paediatric trauma admissions to the five trauma centers in Hong Kong.

\begin{tabular}{|c|c|c|c|c|c|c|c|}
\hline \multirow{2}{*}{ Year } & \multicolumn{2}{|c|}{ Female (Column \%) } & \multicolumn{2}{|c|}{ Male (Column \%) } & \multicolumn{2}{|c|}{ Total (Column \%) } & \multirow[t]{2}{*}{ Pearson Chi sqwuare (df) } \\
\hline & & & & & & & \\
\hline 2009 & 99 & (17.34) & 214 & (19.11) & 313 & $(18.51)$ & $3.646, P=0.724(6)$ \\
\hline 2010 & 119 & $(20.84)$ & 203 & (18.13) & 322 & (19.04) & \\
\hline 2011 & 123 & $(21.54)$ & 253 & $(22.59)$ & 376 & $(22.24)$ & \\
\hline 2012 & 130 & $(22.77)$ & 233 & $(20.80)$ & 363 & $(21.47)$ & \\
\hline 2013 & 100 & $(17.51)$ & 217 & (19.38) & 317 & $(18.75)$ & \\
\hline Total & 571 & & 1120 & & 1691 & & \\
\hline \multicolumn{8}{|l|}{ Month } \\
\hline Jan & 51 & $(8.93)$ & 102 & $(9.11)$ & 153 & $(9.05)$ & $15.33, \mathrm{P}=0.224(12)$ \\
\hline Feb & 40 & $(7.01)$ & 70 & $(6.25)$ & 110 & $(6.51)$ & \\
\hline Mar & 58 & (10.16) & 106 & $(9.46)$ & 164 & $(9.70)$ & \\
\hline Apr & 58 & $(10.16)$ & 102 & $(9.11)$ & 160 & $(9.46)$ & \\
\hline May & 48 & $(8.41)$ & 99 & $(8.84)$ & 147 & $(8.69)$ & \\
\hline Jun & 78 & $(13.66)$ & 109 & (9.73) & 187 & $(11.06)$ & \\
\hline July & 49 & $(8.58)$ & 93 & $(8.30)$ & 142 & $(8.40)$ & \\
\hline Aug & 49 & $(8.58)$ & 94 & (8.39) & 143 & $(8.46)$ & \\
\hline Sept & 37 & $(6.48)$ & 103 & $(9.20)$ & 140 & $(8.28)$ & \\
\hline Oct & 45 & $(7.88)$ & 81 & $(7.23)$ & 126 & $(7.45)$ & \\
\hline Nov & 33 & $(5.78)$ & 80 & $(7.14)$ & 113 & $(6.68)$ & \\
\hline Dec & 25 & $(4.38)$ & 81 & $(7.23)$ & 106 & $(6.27)$ & \\
\hline \multicolumn{8}{|l|}{ Weekday } \\
\hline Sunday & 77 & (13.49) & 166 & (14.82) & 243 & (14.37) & $7.984, \mathrm{P}=0.334(7)$ \\
\hline Monday & 77 & (13.49) & 175 & (15.63) & 252 & $(14.90)$ & \\
\hline Tuesday & 77 & $(13.49)$ & 144 & $(12.86)$ & 221 & $(13.07)$ & \\
\hline Wednesday & 70 & $(12.26)$ & 148 & $(13.21)$ & 218 & (12.89) & \\
\hline Thursday & 68 & (11.91) & 150 & (13.39) & 218 & (12.89) & \\
\hline Friday & 99 & (17.34) & 146 & (13.04) & 245 & $(14.49)$ & \\
\hline Saturday & 103 & (18.04) & 191 & (17.05) & 294 & (17.39) & \\
\hline \multicolumn{8}{|l|}{ Seasons } \\
\hline Spring & 164 & $(28.72)$ & 307 & $(27.41)$ & 471 & $(27.85)$ & $5.966, P=0.202(4)$ \\
\hline Summer & 176 & $(30.82)$ & 296 & $(26.43)$ & 472 & $(27.91)$ & \\
\hline Fall & 115 & (20.14) & 264 & $(23.57)$ & 379 & $(22.41)$ & \\
\hline Winter & 116 & $(20.32)$ & 253 & $(22.59)$ & 369 & $(21.82)$ & \\
\hline
\end{tabular}

female and no association was found as $X^{2}(12, \mathrm{n}=1,691)=15.33$, $\mathrm{p}=0.224$. Even distribution was also observed on weekly and seasonal bases with ranged from $218(12.89 \%)$ to $294(17.39 \%)$ and $369(21.82 \%)$ to $472(27.91 \%)$ respectively. There were also no association between weekdays as $X^{2}(7, \mathrm{n}=1,691)=7.984, \mathrm{p}=0.334$ and seasonal bases as $X^{2}(4, \mathrm{n}=1,691)=5.966, \mathrm{p}=0.202$ (Table 2).

\subsection{Injury prevention score (IPPZ)}

The ISS is calculated by the sum of the square of the top three assigned abbreviated injury score (AIS) while the IPPZ is computed by a process of standardization and $\mathrm{z}$ scores from the frequency and ISS of each features. The IPPZ provide yardstick to prioritize the prevention with consideration of frequency and ISS together. For intent, unintentional trauma (IPPZ of 67.18 , mean ISS $7.8 \pm 8.73, \mathrm{n}=1,514$ ) and selfharm (IPPZ of 50.4 , mean ISS $15.4 \pm 18.41, \mathrm{n}=49$ ) were found to be the top and second prioritized categories for prevention. On the other hand, travelling activities (IPPZ: 59.94, mean ISS $10.2 \pm 10.23$, $\mathrm{n}=402$ ) and leisure activities (IPPZ: 52.04, mean ISS $5.6 \pm 6.77$, $\mathrm{n}=312$ ) were also found to be the top and second prioritized area respectively. Corresponding to the findings from activities, street/ highway (IPPZ: 70.22 , mean ISS $10.48 \pm 10.53, \mathrm{n}=475$ ) and home (including garden and out buildings) (IPPZ: 69.56, mean ISS $6.64 \pm 7.94, n=539$ ) were observed as the top and second prioritized places for preventive consideration. On the other hand, variation of injury severity $(\mathrm{P}<0.05)$ and consumption of hospital bed days $(\mathrm{P}<0.05)$ were observed between centers, which implied the need for further exploring the geographical variation and area level factors (Table 3).

\subsection{Low income population}

The population of low-income (PA) and non-low-income (non-PA) were made from the pay code of the hospital record system where PA group was receiving the government public assistance due to poor financial situation. From the overall population $(n=1,691), 230$ (13.6\%) incidence were identified in PA group. Male also played the major portion in PA group with female to male ratio of 1:2.11. Similar to the non-PA group, unintentional injury ( $\mathrm{n}=198,86.09 \%$ ), travelling activities $(n=68,29.57 \%)$ and were found to be the top features in PA group. However, different findings showed that home (including garden and out buildings) ( $\mathrm{n}=482,28.50 \%)$ and street/highway ( $\mathrm{n}=83,36.09 \%)$ were the top area in PA and non-PA group accordingly. Significant difference were identified by the center distribution $\left(\mathrm{X}^{2} 24.915, \mathrm{p}<0.001, \mathrm{df}=4\right)$, it may due to the geographic variation in socio economic status and area level characteristics. Overall, there were no significant difference in the distribution of injury severity among the features except those being injured at other transport area $(\mathrm{P}=0.041)$ while non PA group was scaled with a higher mean ISS than the PA group (11.80 vs 3.00$)$. Although there was also no significant difference in the consumption of hospital bed days between the two groups, higher consumption of bed days was observed for those work related activities (20.08 days) and industrial/construction area (11.71 days). It could be explained that HK is a safe city with low incidence of trauma and the low-income group is not at a disadvantaged position. They are receiving well government support in the society with easy access to health care service. In addition, the exposure to risk of injury was minimized by the 9-year compulsory education scheme in HK (Table 4). 
Table 3

Injury severity score (ISS) and Injury prevention score (IPPZ) by epidemiological features.

\begin{tabular}{|c|c|c|c|c|c|c|c|c|c|}
\hline & \multicolumn{2}{|c|}{$\mathrm{N}$ (column \%) } & \multicolumn{4}{|l|}{ ISS } & \multirow[t]{2}{*}{ IPPZ } & \multicolumn{2}{|c|}{ Mean consumption of hospital bed days } \\
\hline & & & Mean & CI lower & CI Upper & SD & & (T/F val & istics), P-value, df \\
\hline \multicolumn{10}{|l|}{ Gender } \\
\hline Female & 569 & $(33.65)$ & 8.02 & 7.24 & 8.80 & 9.51 & 42.93 & 11.35 & $1.191, \mathrm{P}=0.234$ \\
\hline Male & 1122 & $(66.35)$ & 7.96 & 7.43 & 8.49 & 9.02 & 57.07 & 8.98 & \\
\hline \multicolumn{10}{|l|}{ Intent } \\
\hline Unintentional & 1514 & (89.53) & 7.80 & 7.36 & 8.24 & 8.73 & 67.18 & 9.57 & $3.687, \mathrm{P}=0.005, \mathrm{df}=4$ \\
\hline Self-harm & 49 & $(2.90)$ & 15.37 & 10.08 & 20.65 & 18.41 & 50.40 & 25.84 & \\
\hline Assault & 89 & $(5.26)$ & 7.21 & 5.65 & 8.77 & 7.40 & 45.00 & 6.30 & \\
\hline Other & 4 & $(0.24)$ & 6.50 & 0.00 & 17.86 & 7.14 & 43.18 & 12.75 & \\
\hline Unknown & 35 & $(2.07)$ & 7.31 & 3.97 & 10.65 & 9.73 & 44.25 & 5.06 & \\
\hline \multicolumn{10}{|l|}{ Activities } \\
\hline Work related & 21 & $(1.24)$ & 8.14 & 2.38 & 13.91 & 12.67 & 38.45 & 19.14 & $1.217, \mathrm{P}=0.295 \mathrm{df}=6$ \\
\hline Educational activities & 16 & $(0.95)$ & 9.69 & 4.82 & 14.55 & 9.13 & 39.24 & 3.45 & \\
\hline Sports & 131 & (7.75) & 6.18 & 5.03 & 7.32 & 6.62 & 42.91 & 4.03 & \\
\hline Leisure activities & 312 & (18.45) & 5.57 & 4.82 & 6.33 & 6.77 & 52.04 & 11.27 & \\
\hline Travelling & 402 & $(23.77)$ & 10.22 & 9.21 & 11.22 & 10.23 & 59.94 & 9.19 & \\
\hline Other & 305 & (18.04) & 8.87 & 7.75 & 9.98 & 9.88 & 53.91 & 9.15 & \\
\hline Unknown & 504 & $(29.80)$ & 7.56 & 6.72 & 8.32 & 9.11 & 63.50 & 11.00 & \\
\hline \multicolumn{10}{|l|}{ Place of Injury } \\
\hline Home, including garden and out buildings & 539 & (31.87) & 6.64 & 5.97 & 7.32 & 7.94 & 69.56 & 9.62 & $0.771, \mathrm{P}=0.669, \mathrm{df}=11$ \\
\hline School, including kindergarten and schoolyard & 46 & $(2.72)$ & 9.65 & 6.68 & 12.62 & 10.00 & 46.33 & 4.32 & \\
\hline Street/highway & 475 & (28.09) & 10.48 & 9.53 & 11.43 & 10.53 & 70.22 & 10.15 & \\
\hline Residential institution & 28 & $(1.66)$ & 8.93 & 4.01 & 13.84 & 12.67 & 44.59 & 5.17 & \\
\hline Sports and athletics area & 122 & $(7.21)$ & 6.13 & 4.95 & 7.31 & 6.60 & 46.64 & 4.91 & \\
\hline Other transport area & 17 & $(1.01)$ & 10.76 & 4.97 & 16.55 & 11.26 & 45.96 & 10.88 & \\
\hline Industrial/construction & 21 & (1.24) & 9.71 & 3.82 & 15.61 & 12.96 & 45.05 & 11.71 & \\
\hline Farm, excluding home & 2 & $(0.12)$ & 9.00 & - & - & - & 43.27 & 3.50 & \\
\hline Commercial & 52 & (3.08) & 5.71 & 3.21 & 8.22 & 9.00 & 42.44 & 9.96 & \\
\hline Countryside, water, sea & 13 & $(0.77)$ & 8.31 & 3.66 & 12.95 & 7.69 & 43.12 & 4.55 & \\
\hline Other & 81 & $(4.79)$ & 7.54 & 5.83 & 9.26 & 7.77 & 45.95 & 7.22 & \\
\hline Unknown & 295 & (17.45) & 7.02 & 6.04 & 8.00 & 8.58 & 56.87 & 13.15 & \\
\hline \multicolumn{10}{|l|}{ Trauma Centers Admission } \\
\hline PMH & 306 & $(18.10)$ & 7.37 & 6.63 & 8.11 & 6.59 & 42.34 & 5.78 & $3.204, \mathrm{P}=0.012, \mathrm{df}=4$ \\
\hline PWH & 354 & (20.93) & 9.79 & 8.72 & 10.86 & 10.25 & 55.24 & 13.43 & \\
\hline QEH & 397 & $(23.48)$ & 10.11 & 9.10 & 11.11 & 10.21 & 65.21 & 8.62 & \\
\hline QMH & 321 & (18.98) & 4.28 & 3.53 & 5.04 & 6.88 & 43.08 & 8.58 & \\
\hline TMH & 313 & $(18.51)$ & 7.62 & 6.56 & 8.68 & 9.52 & 44.13 & 12.18 & \\
\hline
\end{tabular}

\section{Discussion}

\subsection{Main findings}

The result of this study identified the average number of paediatric trauma were 338 per year. The number of male was always greater than female while the gender ratio increased with ages. It might be explained by the behavioral difference between genders along the age continuum. Peak number of incidences occurred at the age of 1 years for the both genders, it was worthy for further exploration on the group. Most of the cases suffered from head/neck injuries $(\mathrm{n}=735,43.47 \%)$ and external injuries which includes open wounds $(\mathrm{n}=238,14.07 \%)$, bruise ( $\mathrm{n}=152,8.9 \%)$ and burns injuries $(\mathrm{n}=302,17.86 \%)$ while a significant population ( $\mathrm{n}=609,36 \%$ ) were scaled with serious to critical injured. Same as western findings that majority of the head injured population was mild in nature ${ }^{20,21}$ and for burn trauma, the majority were related to hot liquid and substance which indicate further study focusing on burn prevention. ${ }^{22}$ On the other hand, fractures $(n=265$, $15.67 \%$ ) are also a concern for the elder age group which represented major portion within the fractures $(n=210,79.25 \%)$. Similar with literature, with increasing age, a decline in the proportion of children with head injury and an increase in the proportion with limb injury were observed. ${ }^{23}$ Unintentional trauma played the major portion and travelling was the top activities within the age of 7-18 years. Alternatively, it was different that leisure activities being the top activities within younger age group below 6 years. The portion played by sport activities also progressively increased from the age of 7 years while the educational activities also maintained a quite low number along the continuum of ages. For the place of injury, home (including garden and out building) and street/highway were the common place of occurrence. In view of mechanism, fall injuries, scald by hot liquid and substance and traffic related incidences were found to be a concern for further exploration and prevention There were more scald injury happened in the aged below 2 years. Similar to western study that motor vehicle traffic injury resulted in the most severe injury, ${ }^{24,25}$ there was increased number of traffic injured with ages. For the temporal consideration, steady observation was made along the temporal features including year, month, weekday and seasons. Low-income population was found to be non-significant factors to identify difference in the epidemiological features. There was also no significant difference between the PA and non-PA group except the distribution of severity at other transport area for non-PA group were higher $(\mathrm{P}=0.041)$.

\subsection{Injury surveillance}

The findings showed the characteristics of selected group of trauma, which represented a small portion of the paediatric injured population like the tips of an iceberg. Injury surveillance should be carried out to collect, analyzing and disseminating the information for describing the overall problem and formulating the prevention strategies in a public health approach. Surveillance information was useful to those who were able to take action to prevent problems, improve health care and mobilize resources and services. ${ }^{26}$ Prospective data collection including the situational variables, process of data collection, instruments, data 
Table 4

Injury severity score (ISS) by epidemiological features among PA and non PA Group.

\begin{tabular}{|c|c|c|c|c|c|c|c|c|c|}
\hline & \multicolumn{3}{|l|}{$\mathrm{N}$} & \multicolumn{3}{|l|}{ ISS } & \multicolumn{3}{|c|}{ Mean consumption of hospital bed days } \\
\hline & Non PA & PA & chi-square Test, (P-value), df & Non PA & PA & $\mathrm{T}$ value (P-value) & Non PA & PA & $\mathrm{T}$ value ( $\mathrm{p}$ value) \\
\hline \multicolumn{10}{|l|}{ Gender } \\
\hline Female & 495 & 74 & $0.259,(0.611), \mathrm{df}=1$ & 7.76 & 9.73 & $1.301(0.197)$ & 10.34 & 17.53 & $0.073(0.178)$ \\
\hline Male & 966 & 156 & & 8.00 & 7.71 & $0.379(0.705)$ & 9.32 & 7.05 & $1.143(0.253)$ \\
\hline \multicolumn{10}{|l|}{ Intent } \\
\hline Unintentional & 1316 & 198 & $5.868,(0.319), \mathrm{df}=5$ & 7.74 & 8.22 & $0.722(0.470)$ & 9.48 & 10.10 & $0.655(0.791)$ \\
\hline Self-harm & 39 & 10 & & 15.56 & 14.60 & $0.146(0.884)$ & 28.49 & 15.56 & $0.582(0.564)$ \\
\hline Assault & 72 & 17 & & 6.97 & 8.24 & $0.631(0.530)$ & 5.12 & 11.19 & $1.726(0.103)$ \\
\hline Other & 3 & 1 & & 8.33 & 1.00 & - & 4.33 & 38.00 & $7.003(0.020)$ \\
\hline Unknown & 31 & 4 & & 8.03 & 1.75 & $3.197(0.003)$ & 5.13 & 4.50 & $0.104(0.917)$ \\
\hline \multicolumn{10}{|l|}{ Activities } \\
\hline Work related & 19 & 2 & $13.629,(0.058), \mathrm{df}=7$ & 8.74 & 2.50 & $0.653(0.522)$ & 20.08 & 7.00 & $0.382(0.709)$ \\
\hline Educational activities & 13 & 3 & & 9.46 & 10.67 & $0.199(0.845)$ & 3.88 & 2.33 & $0.507(0.624)$ \\
\hline Sports & 117 & 14 & & 5.99 & 7.71 & $0.920(0.360)$ & 4.09 & 3.62 & $0.380(0.705)$ \\
\hline Leisure activities & 286 & 26 & & 5.65 & 4.77 & $0.632(0.528)$ & 11.32 & 10.65 & $0.061(0.952)$ \\
\hline Travelling & 334 & 68 & & 10.41 & 9.26 & $0.842(0.400)$ & 8.19 & 13.63 & $0.945(0.348)$ \\
\hline Other & 263 & 42 & & 9.00 & 8.05 & $0.577(0.564)$ & 9.47 & 7.23 & $0.751(0.453)$ \\
\hline Unknown & 429 & 75 & & 7.28 & 9.13 & $1.625(0.105)$ & 11.06 & 10.70 & $0.087(0.931)$ \\
\hline \multicolumn{10}{|l|}{ Place of Injury } \\
\hline Home, including garden and out buildings & 482 & 57 & $13.922,(0.237), \mathrm{df}=11$ & 6.62 & 6.81 & $0.164(0.870)$ & 9.20 & 13.08 & $1.182(0.238)$ \\
\hline $\begin{array}{l}\text { School, including kindergarten and } \\
\text { schoolyard }\end{array}$ & 38 & 8 & & 9.68 & 9.50 & $0.047(0.963)$ & 4.68 & 2.71 & $0.821(0.417)$ \\
\hline Street/highway & 392 & 83 & & 10.56 & 10.10 & $0.365(0.715)$ & 9.43 & 13.28 & $0.793(0.430)$ \\
\hline Residential institution & 25 & 3 & & 9.16 & 7.00 & $0.274(0.786)$ & 5.07 & 5.67 & $0.156(0.878)$ \\
\hline Sports and athletics area & 109 & 13 & & 6.13 & 6.15 & $0.013(0.990)$ & 4.94 & 4.73 & $0.087(0.931)$ \\
\hline Other transport area & 15 & 2 & & 11.80 & 3.00 & $2.443(0.041)$ & 12.13 & 1.50 & $0.729(0.477)$ \\
\hline Industrial/construction & 20 & 1 & & 10.15 & 1.00 & $0.680(0.505)$ & 11.71 & 0.00 & - \\
\hline Farm, excluding home & 2 & - & & 9.00 & - & - & 3.50 & - & - \\
\hline Commercial & 45 & 7 & & 5.73 & 5.57 & $0.044(0.965)$ & 10.82 & 5.29 & $0.648(0.521)$ \\
\hline Countryside, water, sea & 11 & 2 & & 7.45 & 13.00 & $0.457(0.724)$ & 4.80 & 2.00 & $0.751(0.472)$ \\
\hline Other & 69 & 12 & & 7.90 & 5.50 & $0.987(0.326)$ & 7.35 & 6.45 & $0.260(0.795)$ \\
\hline Unknown & 253 & 42 & & 6.68 & 9.07 & $1.279(0.207)$ & 14.30 & 7.17 & $0.753(0.452)$ \\
\hline \multicolumn{10}{|l|}{ Trauma Centers Admission } \\
\hline PMH & 251 & 55 & $24.915,(<0.001), \mathrm{df}=4$ & 7.36 & 7.44 & $0.079(0.937)$ & 5.29 & 7.96 & $1.863(0.063)$ \\
\hline PWH & 313 & 41 & & 9.81 & 9.61 & $0.120(0.904)$ & 13.99 & 9.56 & $0.575(0.566)$ \\
\hline QEH & 340 & 57 & & 10.29 & 8.98 & $0.897(0.370)$ & 8.81 & 7.53 & $0.551(0.582)$ \\
\hline $\mathrm{QMH}$ & 300 & 21 & & 4.36 & 3.19 & $0.752(0.452)$ & 8.38 & 12.00 & $0.671(0.503)$ \\
\hline TMH & 257 & 56 & & 7.18 & 9.64 & $1.764(0.079)$ & 11.22 & 16.22 & $0.826(0.409)$ \\
\hline
\end{tabular}

entry and quality control of data would be the proposed area to improve the understating and planning to handle not only the paediatric trauma population in secondary prevention perspective, but also including those minor to moderate injured population from a primary preventive perspective. ${ }^{27}$

\subsection{Implication for prevention}

IPPZ identified the prioritized area from combined consideration of frequency and injury severity, ${ }^{9}$ unintentional trauma and self-harm were found to be the top and second prioritized categories for prevention. IPPZ might be useful in tailoring injury prevention programs to local population needs. ${ }^{8}$ Same as the features by frequency only, travelling act ivies, leisure activities, home (including garden and out buildings) and street/highway were the prioritized area. Furthermore, area level characteristics should be further explored as the study identified variation of distribution by centers. It might be influenced by the local characteristics in socio economic and physical perspectives. So, further study was proposed in a geographical approach as a supplement for focus preventive measures formulation at area level. In addition, site survey was suggested to identify the environmental factors contributing to occurrence including the condition of ground, playground design, lighting, traffic light arrangement and so on.

\subsection{Limitation}

The data source mainly contributed by the designated five trauma centers in Hong Kong, under reporting should be considered from missed record from other district hospitals. Although prehospital trauma diversion have been implemented in Hong Kong for diversion of trauma to the designated centers, potential missed case still existed due to the varied clinical situations. The issue could be solved by including all hospital with emergency departments in Hong Kong in future study. Given AIS coding were mainly used for clinical evaluation and mortality risk adjustment, further exploration of the IPPZ should be made to correlate the frequency and injury severity in a public health perspective. In addition, only selected features were analyzed in this study due to the limitation of retrospective data retrieval, the problem could be solved by prospective data collection through injury surveillance.

\section{Conclusion}

This study has identified the epidemiological features of paediatric trauma and the related characteristics in the low income group in Hong Kong. In view of the study approach, there was a weakness of case selection as it was a trauma centres based study. It might have less representativeness in respect to the whole population while some minor trauma had been admitted to other district hospitals. Nevertheless, there was a recognized strength of using the IPPZ to adjust the effect of case number and injury severity, which provided a fair view to 
highlight the findings with priorities in the epidemiological features. As guided by IPPZ, unintentional trauma, self-harm, travelling activities, leisure activities, street/highway, home were those areas of concern. Safety promotion in traffic, cycling, handling of hot liquid or substance at home and work place safety for industrial and construction site should be addressed. Although there was no significant temporal trend being identified from this study, additional research about risk and protective factors, and efforts to implement successful injury prevention strategies among the populations at highest risk for injuries are necessary to further reduce the toll on children's lives. ${ }^{28}$ The study provided insights on the clustering characteristics of paediatric trauma for further study initiatives including injury surveillance, geographical analysis and environment survey. This study model could be replicated to explore the characteristics of the overall paediatric injury population for enhancing the understanding that would be beneficial to injury prevention.

\section{References}

1. Sminkey L. World report on child injury prevention. Inj Prev. 2008;14(1):69.

2. Borse NN, et al. Unintentional childhood injuries in the United States: key findings from the CDC childhood injury report. J Saf Res. 2009;40(1):71-74.

3. Borse N, Sleet DA. CDC Childhood Injury Report: Patterns of Unintentional Injuries Among 0- to 19-Year Olds in the United States, 2000-2006. Fam Commun Health 2009;32(2):189.

4. Department of health., Child Health Survey, 2005-2006. 2009: Department of Health - The Goverment of the Hong Kong Special Adminstrative Region.

5. Chan CC, et al. An international comparison of childhood injuries in Hong Kong. Inj Prev. 2000;6(1):20-23.

6. Chan CC, et al. Unintentional residential child injury surveillance in Hong Kong. $J$ Paediatr Child Health. 2003;39(6):420-426.

7. Chow CB, et al. Development of an electronic emergency department-based geo-information injury surveillance system in Hong Kong. Injury. 2012;43(6):739-748.

[8]. Haider AH, et al. Injury prevention priority score: a new method for trauma centers to prioritize injury prevention initiatives. J Am Coll Surg. 2004:198(6):906-913.

9. Haider $\mathrm{AH}$, et al. Determination of national pediatric injury prevention priorities using the Injury prevention priority score. J Pediatr Surg. 2004;39(6):976-978.

10. Chichom-Mefire A, Fokou M. Epidemiology of paediatric injury in low income environment: value of hospital based data prior to the institution of a formal registration system. Afr J Paediatr Surg. 2013;10(3):265-270.

11. Hawley C, et al. Epidemiology of paediatric minor head injury: Comparison of injury characteristics with Indices of Multiple Deprivation. Injury. 2013;44(12):1855-1861.

12. Bhatti KM, et al. Paediatric Blunt Torso Trauma: Injury mechanisms, patterns and outcomes among children requiring hospitalisation at the Sultan Qaboos University Hospital, Oman. Sultan Qaboos Univ Med J. 2016;16(2):e210-6.

13. Cheung NK, et al. Primary trauma diversion: initial experience in Hong Kong. $J$ Trauma. 2006;61(4):954-960.

14. Lui TW, Fan KL, Leung LP. Performance of a prehospital trauma diversion system in Hong Kong: China. Chin J Traumatol. 2015;18(3):137-140.

15. Leung GK, et al. The first 5 years since trauma center designation in the Hong Kong Special Administrative Region: People's Republic of China. J Trauma. 2011;70(5):1128-1133

16. Yeung JH, et al. Bicycle related injuries presenting to a trauma centre in Hong Kong. Injury. 2009;40(5):555-559.

17. Yeung JH, et al. High risk trauma in older adults in Hong Kong: a multicentre study. Injury. 2008;39(9):1034-1041.

18. Leung KK, et al. Outcome of severely injured trauma patients at a designated trauma centre in the Hong Kong special administrative region. Chin Med J (Engl). 2010;123(10):1251-1254.

19. Knoppert D, et al. Paediatric Age Categories to Be Used in Differentiating Between Listing on a Model Essential Medicines List for Children. 2007; 2007.

20. Amaranath JE, et al. Epidemiology of traumatic head injury from a major paediatric trauma centre in New South Wales, Australia. ANZ J Surg. 2014;84(6):424-428.

21. Lam WH, MacKersie A. Paediatric head injury: incidence, aetiology and management. Paediatr Anaesth. 1999;9(5):377-385.

[22]. Tse T, et al. Paediatric burn prevention: an epidemiological approach. Burns. 2006;32(2):229-234.

23. Bayreuther J, et al. Paediatric trauma: injury pattern and mortality in the UK. Arch Dis Child Educ Pract Ed. 2009;94(2):37-41.

24. Cyr C, Xhignesse M, Lacroix J. Severe injury mechanisms in two paediatric trauma centres: Determination of prevention priorities. Paediatr Child Health 2008;13(3):165-170

25. Chong SL, et al. Predictors for moderate to severe paediatric head injury derived from a surveillance registry in the emergency department. Injury. 2015;46(7):1270-1274.

26. Herbert M, Mackenzie SG. Injury surveillance in paediatric hospitals: the Canadian experience. Paediatr Child Health. 2004;9(5):306-308.

27. Bennett S, Grenier D, Medaglia A. The Canadian paediatric surveillance program: a framework for the timely data collection on head injury secondary to suspected child maltreatment. Am J Prev Med. 2008;34(4 Suppl):S140-142.

28. Grossman DC. The history of injury control and the epidemiology of child and adolescent injuries. Future Child. 2000;10(1):23-52 